\title{
Anti-fibrotic treatments for chronic liver diseases: The present and the future
}

\author{
Naoshi Odagiri',*, Tsutomu Matsubara ${ }^{2, *}$, Misako Sato-Matsubara ${ }^{1,3}$, Hideki Fujii ${ }^{4}$, Masaru Enomoto', and \\ Norifumi Kawada ${ }^{1}$
}

Departments of ${ }^{1}$ Hepatology, ${ }^{2}$ Anatomy and Regenerative Biology, ${ }^{3}$ Endowed Laboratory of Synthetic Biology, and ${ }^{4}$ Premier Preventive Medicine, Graduate School of Medicine, Osaka City University, Osaka, Japan

Liver fibrosis reflects tissue scarring in the liver due to the accumulation of excessive extracellular matrix in response to chronically persistent liver injury. Hepatocyte cell death can trigger capillarization of liver sinusoidal endothelial cells, stimulation of immune cells including macrophages and Kupffer cells, and activation of hepatic stellate cells (HSCs), resulting in progression of liver fibrosis. Liver cirrhosis is the terminal state of liver fibrosis and is associated with severe complications, such as liver failure, portal hypertension, and liver cancer. Nevertheless, effective therapy for cirrhosis has not yet been established, and liver transplantation is the only radical treatment for severe cases. Studies investigating HSC activation and regulation of collagen production in the liver have made breakthroughs in recent decades that have advanced the knowledge regarding liver fibrosis pathophysiology. In this review, we summarize molecular mechanisms of liver fibrosis and discuss the development of novel anti-fibrotic therapies. (Clin Mol Hepatol 2021;27:413-424)

Keywords: Fibrosis; Hepatic stellate cells; Myofibroblasts; Extracellular matrix; Drug therapy

\section{INTRODUCTION}

Liver cirrhosis is a late-stage of chronic hepatitis and currently the 11th most common cause of death globally. Decompensated cirrhosis, the most advanced stage of cirrhosis, is accompanied by severe complications, including liver failure, opportunistic infection, and portal hypertension (resulting in ascites, hepatic encephalopathy, or gastroesophageal varices), that threaten the lives of patients. ${ }^{2}$ Cirrhosis is accompanied by extensive tissue scarring and an increase in intrahepatic vascular resistance. Cir-

\begin{abstract}
Abbreviations:
ALD, alcoholic liver disease; ASK1, apoptosis signal-regulating kinase 1; CBP, cyclic AMP-response element binding protein-binding protein; $C C L, C-C$ chemokine ligand; CCL2, C-C motif ligand; $\mathrm{CCl}_{4}$, carbon tetrachloride; CCR, C-C chemokine receptor; CVC, cenicriviroc; CYGB, cytoglobin; DAMPs, damagedassociated molecular patterns; ECM, extracellular matrix; FDA, Food and Drug Administration; FXR, farnesoid X receptor; HBV, hepatitis B virus; HCV, hepatitis C virus; HSCs, hepatic stellate cells; HSP47, heat shock protein 47; HVPG, hepatic venous pressure gradient; ILs, interleukins; LOXL2, lysyl oxidase-like 2; MMPs, matrix metalloproteinases; NAFLD, non-alcoholic fatty liver disease; NASH, nonalcoholic steatohepatitis; NF-kB, nuclear factor-kappa B; NLRP3, NLR family pyrin domain containing 3; NOX, NADPH oxidase; NTZ, nitazoxanide; OCA, obeticholic acid; PAMPs, pathogen-associated molecular patterns; PBC, primary biliary cholangitis; PFD, pirfenidone; PRRs, pattern recognition receptors; qHSCs, quiescent hepatic stellate cells; ROS, reactive oxygen species; SCD1, stearoylcoenzyme A desaturase 1; SVR, sustained virologic response; THR- $\beta$, thyroid hormone receptor beta; TNF-a, tumor necrosis factor- alpha
\end{abstract}

\author{
Corresponding author: Norifumi Kawada \\ Department of Hepatology, Graduate School of Medicine, Osaka City \\ University, 1-4-3 Asahi-machi, Abeno-ku, Osaka-City, Osaka 545-8585, \\ Japan \\ Tel: +81-6-6645-3701, Fax: +81-6-6645-3702 \\ E-mail: kawadanori@med.osaka-cu.ac.jp \\ https://orcid.org/0000-0002-6392-8311
}

*These authors contributed equally to this work. 


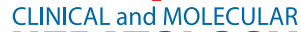

\section{HEPATOLOGY}

Volume_27 Number_3 July 2021

rhosis develops from chronic hepatitis, that can be caused by hepatitis $B$ virus (HBV), hepatitis $C$ virus (HCV), alcoholic liver disease (ALD), non-alcoholic steatohepatitis (NASH), autoimmune hepatitis, and genetic diseases, including hemochromatosis and Wilson's disease. ${ }^{3}$ Recently, progress made in antiviral drugs has contributed to a decrease in viral hepatitis, while the proportion of cirrhosis and liver cancer caused by ALD and NASH has been increasing, particularly in western countries. ${ }^{4}$ Research on liver fibrosis, including the development of cirrhosis therapy, has made remarkable progress. However, effective drugs for cirrhosis treatment are not yet available for clinical use. Development of effective cirrhosis therapies requires the ability to not only target specific cell types, but also to elucidate further mechanisms of liver fibrosis with a comprehensive understanding of intercellular molecular networks. This review will highlight the current status of anti-fibrotic drug development and review the recent studies investigating the molecular mechanisms of liver fibrosis.

\section{POSSIBILITY OF CELL-TARGETING STRATEGY FOR ANTI-FIBROTIC DRUGS}

Liver fibrosis is the most common pathology of cirrhosis and is characterized by progressive accumulation of extracellular matrix (ECM), which destroys the lobule architecture of the liver. ${ }^{5}$ Most of the liver injury is associated with hepatocyte damage. Liver in-

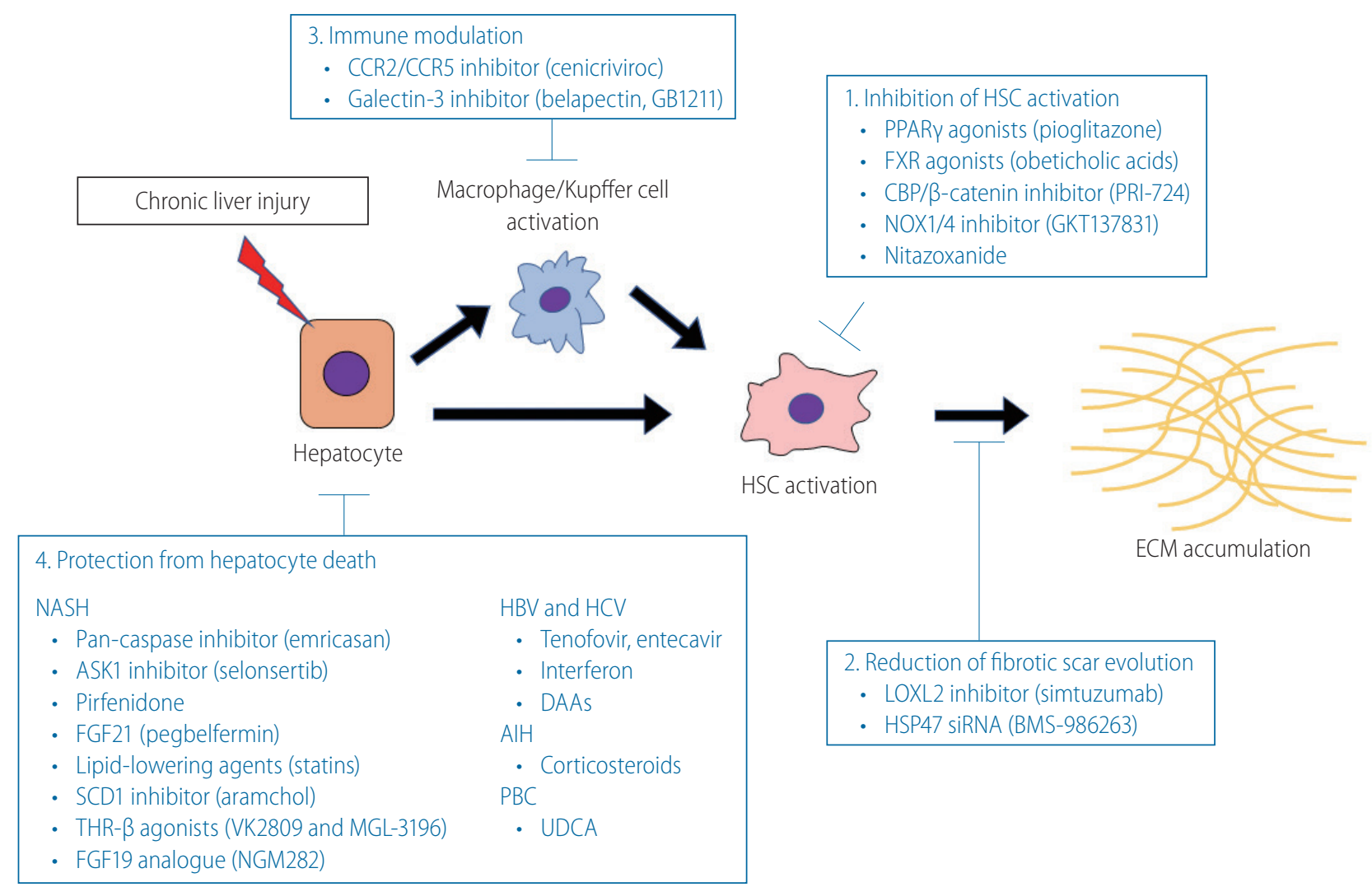

Figure 1. Cell-targeting strategy for anti-fibrotic therapy. Chronic liver injury due to various etiologies causes hepatocyte damage and hepatocyte death. In response to persistent hepatocyte damage, activation of HSCs and macrophages (including Kupffer cells) is induced. Enhanced by activated macrophages, activated HSCs increase and produce excessive ECM, resulting in progression of liver fibrosis. Four major strategies can be utilized to target the interplay between hepatocytes, HSCs, and immune cells involved in the molecular mechanisms associated with collagen accumulation can: 1) inhibition of HSC activation; 2) reduction of fibrotic scar evolution; 3) immune modulation; and 4) protection from hepatocyte death. Numerous drugs that incorporate these strategies are currently being evaluated in clinical trials. CCR, C-C chemokine receptor; HSC, hepatic stellate cell; PPARY, peroxisome proliferator-activated receptor-y; FXR, farnesoid X receptor; CBP, CREB-binding protein; NOX, NADPH oxidase; ECM, extracellular matrix; NASH, non-alcoholic steatohepatitis; ASK1, apoptosis signal-regulating kinase 1; FGF, fibroblast growth factor; SCD1, stearoyl-coenzyme A desaturase 1; THR- $\beta$, thyroid hormone receptor- $\beta$; FGF, fibroblast growth factor; HBV, hepatitis B virus; HCV, hepatitis C virus; DAAs, direct-acting antivirals; AlH, autoimmune hepatitis; PBC, primary biliary cholangitis; UDCA, ursodeoxycholic acid; LOXL2, lysyl oxidase-like 2; HSP47, heat shock protein 47. 
jury induces the accelerated production of ECM components, such as collagens, elastin, and proteoglycans. ${ }^{6}$ This bioadaptive reaction protects hepatocytes from cell death and contributes to liver regeneration. However, persistent liver injury increases activated hepatic stellate cells (HSCs) that produce excessive ECM components, primarily type 1 collagen encoded by the COLIA1 and COLIA2 genes. ' Since the amount of type I collagen in liver tissues results from the equilibrium between type 1 collagen production and the activities of matrix metalloproteinases (MMPs) and tissue inhibitor of MMPs, disruption of the equilibrium can lead to progression of liver fibrosis. ${ }^{8,9}$ In addition, upon liver injury, bone marrow-derived inflammatory cells, including macrophages, accelerate HSC activation with high production of type I collagen. Therefore, strategies for liver fibrosis therapy include: 1) inhibition of HSC activation; 2) reduction of fibrotic scar development; 3) immune modulation; and 4) protection from hepatocyte death (Fig. 1).

Current therapeutic strategies for liver fibrosis rely primarily on the elimination of etiologies. In fact, clinical evidence for liver fibrosis resolution has emerged from studies investigating antiviral therapies for viral hepatitis, ${ }^{10-12}$ lifestyle changes, and bariatric surgery for metabolic liver disease, ${ }^{13}$ suggesting that liver fibrosis is indeed reversible. Table 1 illustrates a portion of the liver fibrosis clinical trials that are currently active or in recruiting phase 1-3. Here, developing anti-fibrotic drugs are summarized from the perspective of cell-targeting strategies.

\section{Inhibition of HSC activation}

HSCs have a quiescent status in healthy liver tissue. Quiescent HSCs (qHSCs) store retinol as retinyl palmitate in lipid droplets. In response to liver injury, $\mathrm{HSCS}$ activate and transdifferentiate into myofibroblast-like cells. ${ }^{7}$ Activated HSCs, characterized by decreased lipid droplets and enhanced expression of a-smooth muscle actin, have a proliferative phenotype and produce excessive ECM components, primarily collagens, resulting in progression of liver fibrosis. ${ }^{15,16} \mathrm{HSC}$ are activated by cytokines, such as interleukins (ILs), tumor necrosis factor- alpha (TNF-a), transforming growth factor- $\beta$ (TGF- $\beta$ ), platelet-derived growth factor, and chemokines, such as monocyte chemoattractant protein-1 (also known as C-C motif ligand 2 [CCL2]), and C-X-C motif ligand 9. Hepatocyte cell death caused by chronic liver injury causes inflammatory activity of liver immune cells, predominantly macrophages, leading to an increase in these secretory factors. ${ }^{17}$ In addition, pathogen-associated molecular patterns (PAMPs) such as lipopolysaccharides released from microbes, DNA, and damaged-associated molecular patterns (DAMPs) derived from damaged hepatocytes, can activate HSCs. PAMPs and DAMPs bind to pattern recognition receptors, such as toll-like receptor 4 , which then enhances the nuclear translocation of nuclear factor-kappa B (NF-KB) via myeloid differentiation primary response 88 , and downregulates the expression of BMP and activin membrane-bound inhibitor, thereby restricting TGF- $\beta$ signaling. ${ }^{18,19}$

Table 1. Current active or recruiting phase 1-3 clinical trials for liver fibrosis (ClinicalTrials.gov)

\begin{tabular}{lllll}
\hline Trial number & \multicolumn{1}{c}{ Drug } & \multicolumn{1}{c}{ Disease } & Phase & Study type \\
\hline NCT03809052 & GB1211 & NASH & Phase 1 & Safety \\
NCT03912532 & NGM282 & NASH & Phase 2 & Efficacy, safety \\
NCT03486899 & BMS-986036 & NAFLD/NASH & Phase 2 & Efficacy, safety \\
NCT03486912 & BMS-986036 & NAFLD/NASH & Phase 2 & Efficacy \\
\hline NCT03205345 & Emricasan & NASH & Phase 2 & Efficacy, safety \\
NCT03656068 & Nitazoxanide & NASH & Phase 2 & Efficacy, safety \\
\hline NCT04099407 & Pirfenidone & CLD & Phase 2 & Efficacy, safety \\
\hline NCT03517540 & Tropifexor and cenicriviroc & NASH & Phase 2 & Efficacy, safety \\
\hline NCT04173065 & VK2809 & NASH & Phase 2 & Efficacy \\
\hline NCT04104321 & Aramchol & NASH & Phase 3 & Efficacy, safety \\
NCT03028740 & Cenicriviroc & NASH & Phase 3 & Efficacy, safety \\
\hline NCT02704403 & Elafibranor & NASH & Phase 3 & Efficacy, safety \\
\hline NCT03900429 & MGL-3196 & NASH & Phase 3 & Efficacy, safety \\
\hline NCT02548351 & Obeticholic Acid & NASH & Phase 3 & Efficacy, safety
\end{tabular}

NASH, non-alcoholic steatohepatitis; NAFLD, non-alcoholic fatty liver disease; CLD, chronic liver disease. 
Peroxisome proliferator-activated receptors (PPARs) are ligandactivated transcription factors of the nuclear hormone receptor superfamily that play major regulatory roles in energy homeostasis and metabolic function. Among the three isoforms of PPARs

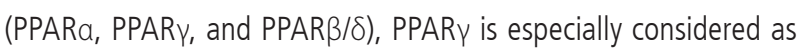
a promising therapeutic target of liver fibrosis. The expression of PPARY decreases HSC activation, though it is highly expressed in quiescent $\mathrm{HSCS}{ }^{20} \mathrm{~A}$ randomized phase 3 clinical trial of pioglitazone, a synthetic insulin sensitizing PPARy agonist, reported improved steatosis and lobular inflammation without a significant effect on fibrosis, in non-cirrhotic NASH patients. ${ }^{21}$ However, a subsequent meta-analysis of eight randomized clinical trials for thiazolidinedione therapy showed that pioglitazone treatment, for up to 24 months, was associated with fibrosis improvement at any stage and NASH resolution. ${ }^{22}$ Moreover, elafibranor is a dual PPARa/ $\delta$ agonist that has shown liver protective effects for steatosis, inflammation, and fibrosis in murine models of non-alcoholic fatty liver disease (NAFLD)/NASH and liver fibrosis. ${ }^{23}$ Results from a post-hoc analysis from a phase 2 trial (NCT01694849) for elafibranor treatment (120 mg/day for 1 year) suggest that it resolved NASH without worsening fibrosis in patients with moderate to severe NASH. ${ }^{24}$ Further, a phase 3 trial (NCT02704403) is currently underway in NASH patients without cirrhosis, with an endpoint defined as resolution of NASH without worsening of fibrosis. However, according to an interim analysis of this trial, elafibranor showed no significant effect on NASH resolution without worsening of fibrosis. ${ }^{25}$

Farnesoid X receptor (FXR), which binds to bile acids as ligands, enhances insulin sensitivity and fatty acid beta-oxidation, while reducing gluconeogenesis and lipogenesis in hepatocytes. ${ }^{26}$ FXR is highly expressed in the small intestine and liver and is also expressed in HSCs. Interestingly, overexpression of FXR inhibited production of collagen in HSCs. ${ }^{27}$ Meanwhile, obeticholic acid (OCA), a semisynthetic derivative of chenodeoxycholic acid, is the selective FXR agonist. In a phase 2 trial, administration of 25 or $50 \mathrm{mg}$ of OCA for 6 weeks increased insulin sensitivity, and reduced markers of liver inflammation and fibrosis in patients with type 2 diabetes mellitus and NAFLD (NCT00501592). ${ }^{28}$ Furthermore, an interim analysis of an ongoing phase 3 study in patients with NASH (NCT02548351) recently reported that daily administration of $25 \mathrm{mg}$ of OCA significantly improved fibrosis by at least one stage without worsening NASH. ${ }^{29}$ Though this report has suggested that NASH patients with non-cirrhotic advanced fibrosis might benefit from OCA treatment, the U.S. Food and Drug Administration (FDA) has not approved OCA for the treatment of
NASH fibrosis and has requested the submission of additional post-interim analyses on the efficacy and safety of the ongoing study. ${ }^{30}$

Wnt/ $\beta$-catenin signaling is associated with the development of tissue fibrosis, including liver fibrosis. ${ }^{31}$ PRI-724, a cyclic AMP-response element binding protein-binding protein (CBP)/ $\beta$-catenin inhibitor, has been shown to inhibit HSC activation and collagen production in HCV transgenic mice. ${ }^{32}$ Additionally, inhibition of $\mathrm{CBP} / \beta$-catenin signaling reportedly attenuated liver fibrosis via reduced hepatocyte apoptosis and suppression of collagen-producing cell activation. According to a phase 1 study, intravenous administration of 10 or $40 \mathrm{mg} / \mathrm{m}^{2} /$ day of PRI-724 over 12 weeks was well tolerated by patients with HCV cirrhosis showing dose dependent histological improvement ( $>2$ points decrease in histologic activity index score) in 3/12 patients, and deterioration by 2 points in $2 / 12$ patients. $^{33} \mathrm{~A}$ phase $1 / 2$ a clinical trial for PRI-724 in patients with hepatitis $B$ or $C$ related liver cirrhosis is ongoing.

Oxidative stress is a known cause of liver fibrosis progression, particularly in NASH. ${ }^{34} \mathrm{NADPH}$ oxidase (NOX) is a common source of reactive oxygen species (ROS) generation, ${ }^{35,36}$ and NOX1, 2, and 4 play important roles in the activation of HSCs. ${ }^{37,38}$ GKT137831, a NOX1/4 inhibitor, suppresses ROS production, NOX, and fibrotic gene expression, while attenuating liver fibrosis in carbon tetrachloride $\left(\mathrm{CCl}_{4}\right)$-induced liver fibrosis in mice. ${ }^{39} \mathrm{~A}$ phase 2 clinical trial for GKT137831 in patients with primary biliary cholangitis (PBC) (NCT03226067) has been completed and results are awaiting publication.

Nitazoxanide (NTZ), an antiprotozoal agent, is the only FDA-approved drug for Cryptosporidium infection. ${ }^{40}$ Recently, NTZ was identified as a potent anti-fibrotic agent by a phenotypic screening approach aimed at discovering a compound capable of interfering with HSC activation. NTZ was found to reduce liver fibrosis in murine models of both $\mathrm{CCl}_{4}$-induced liver fibrosis and diet-induced NASH. ${ }^{41}$ Additionally, NTZ, together with elafibranor, work synergistically to reduce liver fibrosis in a murine NASH model. ${ }^{42} \mathrm{~A}$ phase 2 trial to evaluate the efficacy of NTZ in NASH patients with severe fibrosis is ongoing.

Cytoglobin (CYGB), the fourth human globin, discovered in our laboratory, is most abundantly expressed in HSCs among liver cells. ${ }^{43,44}$ CYGB can bind with oxygen and nitric oxide, and is believed to protect HSCs from ROS. ${ }^{45}$ TGF- $\beta 1$-induced suppression of human $C Y G B$ expression is reported to contribute to the promotion of HSC activation via loss of cellular tolerance to exogenous oxidative stress and oxidative DNA damage in HSCs, resulting in acceleration of liver fibrosis. ${ }^{46}$ Cygb-deficient mice presented with 
progressed liver fibrosis and susceptibility to liver cancer progression in diethylnitrosamine-induced hepatocellular carcinoma and NASH models. ${ }^{47}$ Furthermore, in a rat model, $\mathrm{CCl}_{4}$-induced liver fibrosis was alleviated by administration of recombinant human CYGB protein. ${ }^{48}$ Fibroblast growth factor 2, which enhances CYGB expression, attenuated the progression of liver fibrosis in mice with bile duct ligation. ${ }^{49}$ CYGB protein may, therefore, represent a potential anti-fibrotic drug.

Removal of activated HSCs offers an alternative potential therapeutic strategy for liver fibrosis. Terminal deoxynucleotidyl transferase dUTP nick end labeling-positive HSCs are reportedly increased following reduced liver fibrosis during the recovery process from bile duct ligation-induced liver injury in rats. ${ }^{50}$ Moreover, human and rodent liver myofibroblasts experience constitutive NF-KB activation, which promotes survival by inducing expression of anti-apoptotic genes, such as growth arrest and DNAdamage-inducible 45 beta and B-cell lymphoma $2 .^{51}$ Therefore, studies on the effectiveness of targeted HSC apoptosis as a therapeutic strategy for liver fibrosis are being actively conducted. ${ }^{52,53}$

\section{Reduction of fibrotic scar evolution}

Lysyl oxidase-like 2 (LOXL2) is a copper-dependent amine oxidase secreted by HSCs that contributes to liver fibrosis by catalyzing collagen cross-linking..$^{54,55}$ In murine models of fibrosis, inhibition of LOXL2 by an anti-LOXL2 murine monoclonal antibody decreased liver fibrosis and increased survival. ${ }^{54}$ Meanwhile, simtuzumab, a humanized monoclonal antibody against LOXL2, inhibits the enzymatic activity of LOXL2. ${ }^{56}$ Unfortunately, in two phase $2 \mathrm{~b}$ trials for NASH patients with bridging fibrosis or compensated cirrhosis (NCT01672866 and NCT01672879), simtuzumab failed to decrease hepatic collagen content or hepatic venous pressure gradient (HVPG), respectively. ${ }^{57}$ Similarly, in a phase 2 study on primary sclerosing cholangitis patients (NCT01672853), treatment with simtuzumab for 96 weeks did not reduce fibrosis stage, progression to cirrhosis, or frequency of clinical events. ${ }^{58}$

Collagen 1 accounts for the most abundant collagen in fibrotic livers. ${ }^{59} \mathrm{~A}$ previous study demonstrated that lipid nanoparticles loaded with small interfering RNA (siRNA) against the procollagen a1(I) gene specifically reduced total hepatic collagen content in murine model of liver fibrosis. ${ }^{60}$ Furthermore, another study using transgenic mice with inducible collagen 1 knockdown reported a $40-50 \%$ reduction in hepatic collagen accumulation with additional anti-inflammatory effects. ${ }^{61}$ Meanwhile, heat shock protein 47 (HSP47) is a collagen-specific molecular chaperone essential for procollagen folding in the endoplasmic reticulum. ${ }^{62,63}$ Sato et al. ${ }^{64}$ reported that vitamin A-coupled liposomes carrying siRNA against mRNA encoding rat gp46, a homolog of HSP47, resolved liver fibrosis in a rat model of liver fibrosis. The efficacy of BMS986263, an HSP47 siRNA delivering lipid nanoparticle, has be investigated in patients with F3-4 liver fibrosis (NCT02227459); the interim results for which have demonstrated that BMS-986263 was well tolerated and showed histologic improvement in fibrosis. ${ }^{65}$

\section{Immune modulation}

Infiltrating inflammatory cells, particularly macrophages, are involved in liver fibrosis. PAMPs and DAMPs can stimulate the activation of Kupffer cells, resident macrophages in the liver, and induce immune and inflammatory reactions in the liver. Activated Kupffer cells not only promote HSC activation, but also secrete chemokines, including $\mathrm{C}-\mathrm{C}$ chemokine ligand $(\mathrm{CCL})$ types 2 and 5 (CCL2 and CCL5), which together with their respective receptors, C-C chemokine receptor (CCR) types 2 and 5 (CCR2 and CCR5), contribute to liver inflammation and fibrosis. ${ }^{66-70}$ In response to liver injury, Kupffer cells secrete CCL2 and promote monocyte recruitment to the liver, followed by their maturation into pro-inflammatory LY6C ${ }^{\text {high }}$ macrophages. ${ }^{71,72}$ Pro-inflammatory cytokines released from the macrophages activate HSCs by promoting collagen production. ${ }^{73}$ In fact, a dual CCR2/CCR5 inhibitor, cenicriviroc (CVC) reportedly reduced recruitment of pro-inflammatory macrophages and exerted anti-fibrotic effects in animal models of liver fibrosis. ${ }^{74,75}$ Moreover, a phase $2 \mathrm{~b}$ randomized study (NCT02217475) has reported that after 1 year of CVC treatment, twice as many subjects achieved an improvement in fibrosis without worsening of steatohepatitis, compared with placebo. ${ }^{76} \mathrm{~A}$ rollover study using CVC for the treatment of liver fibrosis in NASH patients is ongoing (NCT03059446). Currently, another rollover study to assess the long-term safety of CVC is being conducted in patients with NASH who have participated in either the CENTAUR study (NCT02217475) or the AURORA study (NCT03028740). Additionally, a combination therapy comprising CVC and tropifexor (an FXR agonist), is under investigation and has reportedly improved inflammation and ballooning in an animal model of NASH. A phase 2 trial of this combination therapy in patients with NASH and liver fibrosis (F2 or 3 ) is ongoing. ${ }^{77}$

Galectin-3 is primarily secreted by activated macrophages and is involved in the pathophysiology of liver fibrosis. ${ }^{78-80}$ Previous studies have demonstrated that belapectin (also known as GRMD-02), an inhibitor or galectin-3, showed potent anti-fibrotic ef- 
ficacy in mouse and rat models of liver fibrosis. ${ }^{81,82}$ While a phase 2b study of belapectin (NCT02462967) did not elicit significant effects on fibrosis following treatment for 52 weeks in patients with NASH, cirrhosis, and portal hypertension, $2 \mathrm{mg} / \mathrm{kg}$ of belapectin effectively reduced HVPG and development of varices in a subgroup analysis of patients without esophageal varices. ${ }^{83} \mathrm{~A}$ phase $2 \mathrm{~b} / 3$ clinical study in patients with NASH cirrhosis without varices is ongoing (NCT04365868). Additionally, GB1211, another galectin-3 receptor inhibitor, is being investigated for its safety and tolerability in a phase 1 study (NCT03809052).

In addition, inflammasomes in hepatic macrophages are important players in liver fibrosis. A well-studied PRR, NLR family pyrin domain containing 3 (NLRP3), forms a complex referred to as the "NLRP3 inflammasome," which produces and secretes inflammatory cytokines. ${ }^{84-86}$ Calvente et al. ${ }^{87}$ demonstrated that neutrophilderived microRNA-223 acts as a silencer of N/rp3 in hepatic macrophages, resulting in attenuated fibrogenesis via inhibition of collagen synthesis in HSCs. Thus, macrophage-specific inhibition of inflammasomes may be a promising strategy for liver fibrosis therapeutics.

\section{Protection from hepatocyte death}

Preventing hepatocyte death by eliminating the cause of hepatocyte injury is one of the most essential treatment strategies for liver fibrosis. Recently, many new drugs to prevent hepatocyte death have been developed and tested, particularly for NASH. In this section, anti-fibrotic drugs targeting hepatocyte injury and death caused by NASH or other factors, are summarized.

\section{NASH}

Previous reports have shown that hepatocyte cell death induces liver inflammation and HSC activation, leading to liver fibrosis progression; hence, inhibition of hepatocyte death could decrease HSC activation in animal models. ${ }^{88,89}$ Recently, randomized placebo-controlled trials for emricasan, a pan-caspase inhibitor, investigated its efficacy in NASH patients. Though emricasan slightly improved HVPG in cirrhotic NASH patients (NCT02960204), ${ }^{90}$ it did not improve liver inflammation or fibrosis, but rather had a tendency to worsen hepatocyte ballooning in patients with NASHassociated F1-F3 fibrosis (NCT02686762). ${ }^{91}$ Furthermore, emricasan did not meet the primary endpoint in a phase $2 \mathrm{~b}$ trial in patients with decompensated NASH cirrhosis (NCT03205345). ${ }^{92}$

Apoptosis signal-regulating kinase 1 (ASK1) is activated by various pathological stimuli, including intracellular oxidative stress and endoplasmic reticulum stress. Activation of ASK1 is involved in hepatocyte apoptosis and necrosis, leading to inflammation and fibrosis in the liver. ${ }^{93-95} \mathrm{~A}$ selective ASK1 inhibitor, selonsertib, was investigated for NASH therapy in a phase 2 clinical trial, and demonstrated improved histological fibrosis in NASH patients with F2-3 fibrosis after 24 weeks of treatment. ${ }^{96}$ However, randomized phase 3 trials in NASH patients with F3 (NCT03053050) and F4 fibrosis (NCT03053063) reported no significant anti-fibrotic effect after 48 weeks of selonsertib monotherapy. ${ }^{97}$

TNF- $a$ also induces hepatocyte death and acute liver failure. 98,99 Apoptotic bodies produced during hepatocyte death are engulfed by Kupffer cells, resulting in enhanced production of death ligands (TNF-a, TRAIL, and FasL) by Kupffer cells and further induction of hepatocyte death. ${ }^{100-102}$ Pirfenidone (PFD), an orally bioavailable pyridone derivative, is approved for the treatment of idiopathic pulmonary fibrosis. ${ }^{103,104} \mathrm{~A}$ previous study has reported that treatment with PFD for 24 months improved hepatic inflammation and fibrosis in patients with chronic hepatitis $\mathrm{C}^{105}$ However, the mechanism of action of PFD has not been fully elucidated. Nevertheless, a recent study reported that PFD attenuated liver fibrosis in western diet-fed melanocortin 4 receptor-deficient mice (NASH model mice). PFD also prevented TNF-a-induced hepatocyte apoptosis with reduced activation of caspase-8 and caspase-3, suggesting that PFD exerts anti-fibrotic effects in NASH via inhibition of hepatocyte death. ${ }^{106}$ A phase 2 study (NCT04099407) evaluating the anti-fibrotic effect and safety of PFD treatment for 12 months in patients with chronic liver diseases has recently reported a significant reduction of fibrosis in 35\% of PFD-treated patients. $^{107}$

BMS-986036 (Pegbelfermin) is a polyethylene glycol-conjugated recombinant analog of human fibroblast growth factor $211^{108,109}$ which is a hepatokine that regulates glucose and lipid metabolism in white adipose tissue. ${ }^{110}$ According to the results of a phase 2 study in NASH patients (NCT02413372), pegbelfermin administration for 16 weeks (10 mg once per day, or 20 mg once per week) significantly reduced both hepatic fat fraction, as measured by magnetic resonance imaging-proton density fat fraction, and mean liver stiffness, as measured by magnetic resonance elastography, compared to the placebo group."11 Phase 2 trials investigating the histologic effects of pegbelfermin are ongoing in NASH patients with bridging fibrosis (NCT03486899), as well as in those with NASH and compensated cirrhosis (NCT03486912), and is projected to be completed in 2021.

Statins which inhibit the activity of hydroxymethylglutaryl-coenzyme A reductase, are applied worldwide as lipid-lowering agents 
for dyslipidemia. Previous studies have reported that statins exert anti-inflammatory and anti-fibrotic effects in animal models of chronic liver diseases. ${ }^{112}$ Although two recent studies, based on retrospective cohort studies, have suggested that statins may be beneficial in decreasing steatosis and fibrosis, as well as for inhibiting disease progression in patients with NAFLD, ${ }^{113,114}$ prospective studies are needed to confirm their effects.

Aramchol is an inhibitor of stearoyl-coenzyme A desaturase 1 (SCD1), which converts saturated fatty acids to monounsaturated fatty acids. Inhibition of SCD1 decreases fatty acid synthesis, which in turn reduces liver fat with improved insulin resistance. ${ }^{115}$ In a phase 2 trial (NCT01094158), administration of aramchol for three months significantly reduced liver fat content in NAFLD patients. ${ }^{116}$ Meanwhile, a phase 3 trial evaluating the efficacy of aramchol in NASH patients with fibrosis, is ongoing.

Thyroid hormone receptor beta (THR- $\beta$ ), which is highly expressed in hepatocytes, regulates lipid metabolism in the liver. ${ }^{117}$ VK2809 and resmetirom (MGL-3196) are THR- $\beta$ agonists that can activate lipid metabolism leading to improvements in NASH. ${ }^{118}$ Phase 2 trials for these drugs have reported a reduction in liver fat and low-density lipoprotein cholesterol. ${ }^{119,120}$ Additionally, VK2809 is being investigated for its efficacy and safety in a phase $2 \mathrm{~b}$ trial for NASH patients (NCT04173065), while resmetirom is being assessed in a phase 3 trial for NASH patients with F2-3 fibrosis (NCT03900429).

FGF19 is a hormone involved in the regulation of bile acid metabolism. ${ }^{121}$ Previous studies have reported reduced concentrations of circulating FGF19 and elevated bile acid concentration in NAFLD patients, ${ }^{122,123}$ suggesting that FGF19 dysregulation might be involved in NASH progression. NGM282, an FGF19 analog, inhibits bile acid synthesis without FGF19-related hepatocarcinogenesis. ${ }^{124,125}$ In mouse models of NASH, NGM282 exerts anti-steatotic, anti-inflammatory, and antifibrotic effects without promoting liver tumorigenesis. ${ }^{126} \mathrm{~A}$ recent phase 2 trial (NCT02443116) has demonstrated that NGM282 reduces liver fat content, as well as markers of liver inflammation and fibrosis in NASH patients. ${ }^{127}$

\section{Alternative causes of liver fibrosis}

The development of antiviral agents against HBV and HCV is the most successful strategy to prevent liver fibrosis progression. In a trial including 348 patients with chronic hepatitis B, antiviral therapy with tenofovir resulted in regression of liver fibrosis in $51 \%$ of the participants, including patients with cirrhosis. ${ }^{10}$ Other reports have shown that long-term viral suppression with entecavir lead to histologic improvement of liver fibrosis. ${ }^{11,128,129}$ Similarly, sustained virologic response (SVR) by antiviral therapy for chronic HCV infection is also associated with liver fibrosis regression. A study reported that $50-60 \%$ of cirrhosis patients who achieved SVR by interferon therapy experienced histological regression of liver fibrosis. ${ }^{12,130}$ Patients who achieved SVR following treatment with direct-acting antiviral agents also experienced liver fibrosis regression. ${ }^{131,132}$

Corticosteroids and immunosuppressive agents are the primary drugs used to treat autoimmune hepatitis. In fact, corticosteroids have been shown to improve liver fibrosis in two-thirds of patients with autoimmune hepatitis. ${ }^{133}$ Meanwhile, immunosuppressive therapies are not effective for PBC. However, ursodeoxycholic acid, the essential drug for $\mathrm{PBC}$, reportedly delays the progression of liver fibrosis in patients with early stage $\mathrm{PBC}$. $^{134}$

\section{CONCLUSIONS}

Liver fibrosis, including cirrhosis, is believed to be potentially reversible. Hence, it is essential to improve liver fibrosis to treat the underlying liver disorder. Many anti-fibrotic drugs targeting hepatocytes, HSCs, and immune cells are being investigated in clinical trials. However, the results of many of these trials suggest that treatment with single agents is not sufficient to ameliorate advanced liver fibrosis. Therefore, combination therapies comprising drugs that act on different mechanisms should be further investigated, along with the development of anti-fibrotic drugs with novel mechanisms. In the near future, therapeutic agents for liver cirrhosis will progress toward clinical application, exploiting the reversibility of liver fibrosis as a primary strategy.

\section{Authors' contribution}

N.O. and T.M. wrote the manuscript and prepared the figures and tables. N.O., T.M., M.S.M., H.F., M.E., and N.K. revised the manuscript.

\section{Acknowledgements}

N.K. was supported by a Grant-in-Aid for Scientific Research from the Japan Society for the Promotion of Science (JSPS) through Grant No. J192640002 (2019-2022) and by the Japan Agency for Medical Research and Development (AMED, 20192022). 


\section{Conflicts of Interest}

The authors have no conflicts to disclose.

\section{REFERENCES}

1. Asrani SK, Devarbhavi H, Eaton J, Kamath PS. Burden of liver diseases in the world. J Hepatol 2019;70:151-171.

2. European Association for the Study of the Liver. EASL clinical practice guidelines for the management of patients with decompensated cirrhosis. J Hepatol 2018;69:406-460.

3. Zhou WC, Zhang QB, Qiao L. Pathogenesis of liver cirrhosis. World J Gastroenterol 2014;20:7312-7324.

4. Pimpin L, Cortez-Pinto H, Negro F, Corbould E, Lazarus JV, Webber $L$, et al. Burden of liver disease in Europe: epidemiology and analysis of risk factors to identify prevention policies. J Hepatol 2018;69:718-735.

5. Iredale JP. Models of liver fibrosis: exploring the dynamic nature of inflammation and repair in a solid organ. J Clin Invest 2007;117: 539-548.

6. Friedman SL. Mechanisms of hepatic fibrogenesis. Gastroenterology 2008;134:1655-1669.

7. Tsuchida T, Friedman SL. Mechanisms of hepatic stellate cell activation. Nat Rev Gastroenterol Hepatol 2017;14:397-411.

8. Wynn TA. Common and unique mechanisms regulate fibrosis in various fibroproliferative diseases. J Clin Invest 2007;117:524-529.

9. Geervliet E, Bansal R. Matrix metalloproteinases as potential biomarkers and therapeutic targets in liver diseases. Cells 2020; 9:1212.

10. Marcellin P, Gane E, Buti M, Afdhal N, Sievert W, Jacobson IM, et al. Regression of cirrhosis during treatment with tenofovir disoproxil fumarate for chronic hepatitis B: a 5-year open-label followup study. Lancet 2013;381:468-475.

11. Chang TT, Liaw YF, Wu SS, Schiff E, Han KH, Lai CL, et al. Longterm entecavir therapy results in the reversal of fibrosis/cirrhosis and continued histological improvement in patients with chronic hepatitis B. Hepatology 2010;52:886-893.

12. D'Ambrosio R, Aghemo A, Rumi MG, Ronchi G, Donato MF, Paradis $V$, et al. A morphometric and immunohistochemical study to assess the benefit of a sustained virological response in hepatitis $C$ virus patients with cirrhosis. Hepatology 2012;56:532-543.

13. Vilar-Gomez E, Martinez-Perez Y, Calzadilla-Bertot L, TorresGonzalez A, Gra-Oramas B, Gonzalez-Fabian L, et al. Weight loss through lifestyle modification significantly reduces features of nonalcoholic steatohepatitis. Gastroenterology 2015;149:367-378.e5; quiz e14-e15.

14. Maher JJ, Bissell DM, Friedman SL, Roll FJ. Collagen measured in primary cultures of normal rat hepatocytes derives from lipocytes within the monolayer. J Clin Invest 1988;82:450-459.

15. Kawada N, Klein H, Decker K. Eicosanoid-mediated contractility of hepatic stellate cells. Biochem J 1992;285(Pt 2):367-371.

16. Pinzani M, Failli P, Ruocco C, Casini A, Milani S, Baldi E, et al. Fat-storing cells as liver-specific pericytes. Spatial dynamics of agonist-stimulated intracellular calcium transients. J Clin Invest 1992;90:642-646.

17. Koyama Y, Brenner DA. Liver inflammation and fibrosis. J Clin Invest 2017;127:55-64.

18. Seki E, De Minicis S, Osterreicher $\mathrm{CH}$, Kluwe J, Osawa Y, Brenner DA, et al. TLR4 enhances TGF-beta signaling and hepatic fibrosis. Nat Med 2007;13:1324-1332.

19. Liu C, Chen X, Yang L, Kisseleva T, Brenner DA, Seki E. Transcriptional repression of the transforming growth factor $\beta$ (TGF- $\beta$ ) pseudoreceptor BMP and activin membrane-bound inhibitor (BAMBI) by nuclear factor $\mathrm{KB}$ (NF-KB) p50 enhances TGF- $\beta$ signaling in hepatic stellate cells. J Biol Chem 2014;289:7082-7091.

20. Yang L, Chan CC, Kwon OS, Liu S, McGhee J, Stimpson SA, et al. Regulation of peroxisome proliferator-activated receptorgamma in liver fibrosis. Am J Physiol Gastrointest Liver Physiol 2006;291:G902-G911.

21. Sanyal AJ, Chalasani N, Kowdley KV, McCullough A, Diehl AM, Bass NM, et al. Pioglitazone, vitamin $E$, or placebo for nonalcoholic steatohepatitis. N Engl J Med 2010;362:1675-1685.

22. Musso G, Cassader M, Paschetta E, Gambino R. Thiazolidinediones and advanced liver fibrosis in nonalcoholic steatohepatitis: a metaanalysis. JAMA Intern Med 2017;177:633-640.

23. Staels B, Rubenstrunk A, Noel B, Rigou G, Delataille P, Millatt LJ, et al. Hepatoprotective effects of the dual peroxisome proliferatoractivated receptor alpha/delta agonist, GFT505, in rodent models of nonalcoholic fatty liver disease/nonalcoholic steatohepatitis. Hepatology 2013;58:1941-1952.

24. Ratziu V, Harrison SA, Francque S, Bedossa P, Lehert P, Serfaty L, et al. Elafibranor, an agonist of the peroxisome proliferator-activated receptor- $\alpha$ and $-\delta$, induces resolution of nonalcoholic steatohepatitis without fibrosis worsening. Gastroenterology 2016;150:11471159.e5.

25. GENFIT. GENFIT: announces results from interim analysis of RESOLVE-IT Phase 3 trial of elafibranor in adults with NASH and fibrosis. GENFIT web site, <https://ml-eu.globenewswire.com/ Resource/Download/38e085e1-66f5-4251-8abe-648d0e7b9ed1>. Accessed 20 Jul 2020.

26. Rotman Y, Sanyal AJ. Current and upcoming pharmacotherapy for non-alcoholic fatty liver disease. Gut 2017;66:180-190.

27. Mann J, Mann DA. Transcriptional regulation of hepatic stellate cells. Adv Drug Deliv Rev 2009;61:497-512.

28. Mudaliar S, Henry RR, Sanyal AJ, Morrow L, Marschall HU, Kipnes 
$M$, et al. Efficacy and safety of the farnesoid $X$ receptor agonist obeticholic acid in patients with type 2 diabetes and nonalcoholic fatty liver disease. Gastroenterology 2013;145:574-582.e1.

29. Younossi ZM, Ratziu V, Loomba R, Rinella M, Anstee QM, Goodman $Z$, et al. Obeticholic acid for the treatment of non-alcoholic steatohepatitis: interim analysis from a multicentre, randomised, placebo-controlled phase 3 trial. Lancet 2019;394:2184-2196.

30. Intercept Pharmaceuticals. Intercept receives complete response letter from FDA for obeticholic acid for the treatment of fibrosis due to NASH. Intercept Pharmaceuticals web site, <https:// ir.interceptpharma.com/node/13671/pdf>. Accessed 20 Jul 2020.

31. Nishikawa K, Osawa Y, Kimura K. Wnt/B-catenin signaling as a potential target for the treatment of liver cirrhosis using antifibrotic drugs. Int J Mol Sci 2018;19:3103.

32. Tokunaga Y, Osawa Y, Ohtsuki T, Hayashi Y, Yamaji K, Yamane D, et al. Selective inhibitor of Wnt/ $\beta$-catenin/CBP signaling ameliorates hepatitis $C$ virus-induced liver fibrosis in mouse model. Sci Rep 2017;7:325.

33. Kimura K, Ikoma A, Shibakawa M, Shimoda S, Harada K, Saio M, et al. Safety, tolerability, and preliminary efficacy of the anti-fibrotic small molecule PRI-724, a CBP/ $\beta$-catenin inhibitor, in patients with hepatitis C virus-related cirrhosis: a single-center, open-label, dose escalation phase 1 trial. EBioMedicine 2017;23:79-87.

34. Schuppan D, Surabattula R, Wang XY. Determinants of fibrosis progression and regression in NASH. J Hepatol 2018;68:238-250.

35. Altenhöfer $S$, Kleikers PW, Radermacher KA, Scheurer P, Rob Hermans JJ, Schiffers $P$, et al. The NOX toolbox: validating the role of NADPH oxidases in physiology and disease. Cell Mol Life Sci 2012:69:2327-2343.

36. Drummond GR, Selemidis S, Griendling KK, Sobey CG. Combating oxidative stress in vascular disease: NADPH oxidases as therapeutic targets. Nat Rev Drug Discov 2011;10:453-471.

37. Jiang JX, Chen $X$, Serizawa N, Szyndralewiez C, Page P, Schröder $K$, et al. Liver fibrosis and hepatocyte apoptosis are attenuated by GKT137831, a novel NOX4/NOX1 inhibitor in vivo. Free Radic Biol Med 2012;53:289-296.

38. Paik YH, Iwaisako K, Seki E, Inokuchi S, Schnabl B, Osterreicher $\mathrm{CH}$, et al. The nicotinamide adenine dinucleotide phosphate oxidase (NOX) homologues NOX1 and NOX2/gp91(phox) mediate hepatic fibrosis in mice. Hepatology 2011;53:1730-1741.

39. Aoyama T, Paik YH, Watanabe S, Laleu B, Gaggini F, FiorasoCartier $\mathrm{L}$, et al. Nicotinamide adenine dinucleotide phosphate oxidase in experimental liver fibrosis: GKT137831 as a novel potential therapeutic agent. Hepatology 2012;56:2316-2327.

40. Rossignol JF. Nitazoxanide: a first-in-class broad-spectrum antiviral agent. Antiviral Res 2014;110:94-103.

41. Belanger C, Foucart C, Negro E, Dubernet M, Hum DW, Staels B, et al. Drug repurposing screen identifies novel small molecule com- pounds with potent antifibrotic properties. J Hepatol 2017;66:S605.

42. Walczak R, Carole B, Benoit N, Descamps E, Nathalie D, Megnien S, et al. Elafibranor and nitazoxanide synergize to reduce fibrosis in a NASH model. J Hepatol 2018;68:S352-S353.

43. Burmester T, Ebner B, Weich B, Hankeln T. Cytoglobin: a novel globin type ubiquitously expressed in vertebrate tissues. Mol Biol Evol 2002;19:416-421.

44. Kawada N, Kristensen DB, Asahina K, Nakatani K, Minamiyama Y, Seki $S$, et al. Characterization of a stellate cell activation-associated protein (STAP) with peroxidase activity found in rat hepatic stellate cells. J Biol Chem 2001;276:25318-25323.

45. Thuy LTT, Hai H, Kawada N. Role of cytoglobin, a novel radical scavenger, in stellate cell activation and hepatic fibrosis. Clin Mol Hepatol 2020;26:280-293.

46. Okina Y, Sato-Matsubara M, Matsubara T, Daikoku A, Longato L, Rombouts $K$, et al. TGF- $\beta 1$-driven reduction of cytoglobin leads to oxidative DNA damage in stellate cells during non-alcoholic steatohepatitis. J Hepatol 2020;73:882-895

47. Thuy le TT, Morita T, Yoshida K, Wakasa K, lizuka M, Ogawa T, et al. Promotion of liver and lung tumorigenesis in DEN-treated cytoglobin-deficient mice. Am J Pathol 2011;179:1050-1060.

48. Li Z, Wei W, Chen B, Cai G, Li X, Wang P, et al. The effect of rhCygb on CCl4-induced hepatic fibrogenesis in rat. Sci Rep 2016;6:23508.

49. Sato-Matsubara M, Matsubara T, Daikoku A, Okina $Y$, Longato $L$, Rombouts $\mathrm{K}$, et al. Fibroblast growth factor 2 (FGF2) regulates cytoglobin expression and activation of human hepatic stellate cells via JNK signaling. J Biol Chem 2017;292:18961-18972.

50. Issa R, Williams E, Trim N, Kendall T, Arthur MJ, Reichen J, et al. Apoptosis of hepatic stellate cells: involvement in resolution of biliary fibrosis and regulation by soluble growth factors. Gut 2001;48:548-557.

51. Watson MR, Wallace K, Gieling RG, Manas DM, Jaffray E, Hay RT, et al. NF-kappaB is a critical regulator of the survival of rodent and human hepatic myofibroblasts. J Hepatol 2008;48:589-597.

52. Zhang Y, Yue D, Cheng L, Huang A, Tong N, Cheng P. Vitamin Acoupled liposomes carrying TLR4-silencing shRNA induce apoptosis of pancreatic stellate cells and resolution of pancreatic fibrosis. J Mol Med (Berl) 2018;96:445-458.

53. Ezhilarasan D, Sokal E, Najimi M. Hepatic fibrosis: it is time to go with hepatic stellate cell-specific therapeutic targets. Hepatobiliary Pancreat Dis Int 2018;17:192-197.

54. Barry-Hamilton V, Spangler R, Marshall D, McCauley S, Rodriguez HM, Oyasu M, et al. Allosteric inhibition of lysyl oxidase-like-2 impedes the development of a pathologic microenvironment. Nat Med 2010;16:1009-1017.

55. Liu SB, Ikenaga N, Peng ZW, Sverdlov DY, Greenstein A, Smith V, et al. Lysyl oxidase activity contributes to collagen stabilization during liver fibrosis progression and limits spontaneous fibrosis reversal in 
mice. FASEB J 2016;30:1599-1609.

56. Rodriguez HM, Vaysberg M, Mikels A, McCauley S, Velayo AC, Garcia $C$, et al. Modulation of lysyl oxidase-like 2 enzymatic activity by an allosteric antibody inhibitor. J Biol Chem 2010;285:2096420974.

57. Harrison SA, Abdelmalek MF, Caldwell S, Shiffman ML, Diehl AM, Ghalib R, et al. Simtuzumab is ineffective for patients with bridging fibrosis or compensated cirrhosis caused by nonalcoholic steatohepatitis. Gastroenterology 2018;155:1140-1153.

58. Muir AJ, Levy C, Janssen HLA, Montano-Loza AJ, Shiffman ML, Caldwell $S$, et al. Simtuzumab for primary sclerosing cholangitis: phase 2 study results with insights on the natural history of the disease. Hepatology 2019;69:684-698.

59. Karsdal MA, Nielsen SH, Leeming DJ, Langholm LL, Nielsen MJ, Manon-Jensen $\mathrm{T}$, et al. The good and the bad collagens of fibrosis - their role in signaling and organ function. Adv Drug Deliv Rev 2017;121:43-56.

60. Jiménez Calvente C, Sehgal A, Popov Y, Kim YO, Zevallos V, Sahin U, et al. Specific hepatic delivery of procollagen a1(I) small interfering RNA in lipid-like nanoparticles resolves liver fibrosis. Hepatology 2015;62:1285-1297.

61. Molokanova O, Schönig K, Weng SY, Wang X, Bros M, Diken M, et al. Inducible knockdown of procollagen I protects mice from liver fibrosis and leads to dysregulated matrix genes and attenuated inflammation. Matrix Biol 2018;66:34-49.

62. Tasab M, Batten MR, Bulleid NJ. Hsp47: a molecular chaperone that interacts with and stabilizes correctly-folded procollagen. EMBO J 2000;19:2204-2211.

63. Ito S, Nagata K. Biology of Hsp47 (Serpin H1), a collagen-specific molecular chaperone. Semin Cell Dev Biol 2017;62:142-151.

64. Sato Y, Murase K, Kato J, Kobune M, Sato T, Kawano Y, et al. Resolution of liver cirrhosis using vitamin A-coupled liposomes to deliver siRNA against a collagen-specific chaperone. Nat Biotechnol 2008;26:431-442.

65. Lawitz E, Tanaka Y, Poordad F, Gutierrez J, Carr K, Ying W, et al. Safety, pharmacokinetics, and biologic activity of ND-L02-s0201, a novel targeted lipid-nanoparticle to deliver HSP47 siRNA for the treatment of patients with advanced liver fibrosis: interim results from clinical phase 1b/2 studies. Hepatology 2015;62:909A.

66. Schwabe RF, Bataller R, Brenner DA. Human hepatic stellate cells express CCR5 and RANTES to induce proliferation and migration. Am J Physiol Gastrointest Liver Physiol 2003;285:G949-G958.

67. Seki E, De Minicis S, Gwak GY, Kluwe J, Inokuchi S, Bursill CA, et al. CCR1 and CCR5 promote hepatic fibrosis in mice. J Clin Invest 2009;119:1858-1870.

68. Seki E, de Minicis S, Inokuchi S, Taura K, Miyai K, van Rooijen $\mathrm{N}$, et al. CCR2 promotes hepatic fibrosis in mice. Hepatology 2009;50:185-197.
69. Mitchell C, Couton D, Couty JP, Anson M, Crain AM, Bizet V, et al. Dual role of CCR2 in the constitution and the resolution of liver fibrosis in mice. Am J Pathol 2009;174:1766-1775.

70. Berres ML, Koenen RR, Rueland A, Zaldivar MM, Heinrichs D, Sahin $\mathrm{H}$, et al. Antagonism of the chemokine $\mathrm{Ccl} 5$ ameliorates experimental liver fibrosis in mice. J Clin Invest 2010;120:4129-4140.

71. Karlmark KR, Weiskirchen R, Zimmermann HW, Gassler N, Ginhoux

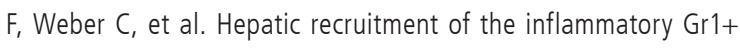
monocyte subset upon liver injury promotes hepatic fibrosis. Hepatology 2009;50:261-274.

72. Miura K, Yang L, van Rooijen N, Ohnishi H, Seki E. Hepatic recruitment of macrophages promotes nonalcoholic steatohepatitis through CCR2. Am J Physiol Gastrointest Liver Physiol 2012;302:G1310- G1321.

73. Pradere JP, Kluwe J, De Minicis S, Jiao JJ, Gwak GY, Dapito DH, et al. Hepatic macrophages but not dendritic cells contribute to liver fibrosis by promoting the survival of activated hepatic stellate cells in mice. Hepatology 2013;58:1461-1473.

74. Lefebvre E, Moyle G, Reshef R, Richman LP, Thompson M, Hong $F$, et al. Antifibrotic effects of the dual CCR2/CCR5 antagonist cenicriviroc in animal models of liver and kidney fibrosis. PLoS One 2016;11:e0158156.

75. Mossanen JC, Krenkel O, Ergen C, Govaere O, Liepelt A, Puengel T, et al. Chemokine ( $\mathrm{C}-\mathrm{C}$ motif) receptor 2-positive monocytes aggravate the early phase of acetaminophen-induced acute liver injury. Hepatology 2016;64:1667-1682.

76. Friedman SL, Ratziu V, Harrison SA, Abdelmalek MF, Aithal GP, Caballeria J, et al. A randomized, placebo-controlled trial of cenicriviroc for treatment of nonalcoholic steatohepatitis with fibrosis. Hepatology 2018;67:1754-1767.

77. Pedrosa M, Seyedkazemi S, Francque S, Sanyal A, Rinella M, Charlton $M$, et al. A randomized, double-blind, multicenter, phase $2 b$ study to evaluate the safety and efficacy of a combination of tropifexor and cenicriviroc in patients with nonalcoholic steatohepatitis and liver fibrosis: study design of the TANDEM trial. Contemp Clin Trials 2020;88:105889.

78. Yang RY, Hsu DK, Liu FT. Expression of galectin-3 modulates T-cell growth and apoptosis. Proc Natl Acad Sci U S A 1996;93:6737-6742.

79. Jeng KC, Frigeri LG, Liu FT. An endogenous lectin, galectin-3 (epsilon BP/Mac-2), potentiates IL-1 production by human monocytes. Immunol Lett 1994;42:113-116.

80. Sano H, Hsu DK, Yu L, Apgar JR, Kuwabara I, Yamanaka T, et al. Human galectin-3 is a novel chemoattractant for monocytes and macrophages. J Immunol 2000;165:2156-2164.

81. Traber PG, Zomer E. Therapy of experimental NASH and fibrosis with galectin inhibitors. PLoS One 2013;8:e83481.

82. Traber PG, Chou H, Zomer E, Hong F, Klyosov A, Fiel MI, et al. Regression of fibrosis and reversal of cirrhosis in rats by galec- 
tin inhibitors in thioacetamide-induced liver disease. PLoS One 2013;8:e75361.

83. Chalasani N, Abdelmalek MF, Garcia-Tsao G, Vuppalanchi R, Alkhouri $N$, Rinella $M$, et al. Effects of belapectin, an inhibitor of galectin-3, in patients with nonalcoholic steatohepatitis with cirrhosis and portal hypertension. Gastroenterology 2020;158:1334-1345.e5.

84. Strowig T, Henao-Mejia J, Elinav E, Flavell R. Inflammasomes in health and disease. Nature 2012;481:278-286.

85. Szabo G, Csak T. Inflammasomes in liver diseases. J Hepatol 2012;57:642-654.

86. Gross O, Thomas CJ, Guarda G, Tschopp J. The inflammasome: an integrated view. Immunol Rev 2011;243:136-151.

87. Calvente CJ, Tameda M, Johnson CD, Del Pilar H, Lin YC, Adronikou $\mathrm{N}$, et al. Neutrophils contribute to spontaneous resolution of liver inflammation and fibrosis via microRNA-223. J Clin Invest 2019;129:4091-4109.

88. Thapaliya S, Wree A, Povero D, Inzaugarat ME, Berk M, Dixon L, et al. Caspase 3 inactivation protects against hepatic cell death and ameliorates fibrogenesis in a diet-induced NASH model. Dig Dis Sci 2014;59:1197-1206.

89. Witek RP, Stone WC, Karaca FG, Syn WK, Pereira TA, Agboola KM, et al. Pan-caspase inhibitor VX-166 reduces fibrosis in an animal model of nonalcoholic steatohepatitis. Hepatology 2009;50:14211430.

90. Garcia-Tsao G, Bosch J, Kayali Z, Harrison SA, Abdelmalek MF, Lawitz $\mathrm{E}$, et al. Randomized placebo-controlled trial of emricasan for non-alcoholic steatohepatitis-related cirrhosis with severe portal hypertension. J Hepatol 2020;72:885-895.

91. Harrison SA, Goodman Z, Jabbar A, Vemulapalli R, Younes $\mathrm{ZH}$, Freilich $\mathrm{B}$, et al. A randomized, placebo-controlled trial of emricasan in patients with NASH and F1-F3 fibrosis. J Hepatol 2020;72:816-827.

92. Kim K, Kim KH. Targeting of secretory proteins as a therapeutic strategy for treatment of nonalcoholic steatohepatitis (NASH). Int J Mol Sci 2020;21:2296.

93. Yamamoto E, Dong YF, Kataoka K, Yamashita T, Tokutomi Y, Matsuba $\mathrm{S}$, et al. Olmesartan prevents cardiovascular injury and hepatic steatosis in obesity and diabetes, accompanied by apoptosis signal regulating kinase-1 inhibition. Hypertension 2008;52:573-580.

94. Wang PX, Ji YX, Zhang XJ, Zhao LP, Yan ZZ, Zhang P, et al. Targeting CASP8 and FADD-like apoptosis regulator ameliorates nonalcoholic steatohepatitis in mice and nonhuman primates. Nat Med 2017;23:439-449.

95. Sumida Y, Yoneda M. Current and future pharmacological therapies for NAFLD/NASH. J Gastroenterol 2018:53:362-376.

96. Loomba R, Lawitz E, Mantry PS, Jayakumar S, Caldwell SH, Arnold $\mathrm{H}$, et al. The ASK1 inhibitor selonsertib in patients with nonalcoholic steatohepatitis: a randomized, phase 2 trial. Hepatology
2018:67:549-559.

97. Harrison SA, Wong VW, Okanoue T, Bzowej N, Vuppalanchi R, Younes $Z$, et al. Selonsertib for patients with bridging fibrosis or compensated cirrhosis due to NASH: results from randomized phase III STELLAR trials. J Hepatol 2020;73:26-39.

98. Luedde T, Beraza N, Kotsikoris V, van Loo G, Nenci A, De Vos $\mathrm{R}$, et al. Deletion of NEMO/IKKgamma in liver parenchymal cells causes steatohepatitis and hepatocellular carcinoma. Cancer Cell 2007;11:119-132.

99. Luedde T, Assmus U, Wüstefeld T, Meyer zu Vilsendorf A, Roskams T, Schmidt-Supprian M, et al. Deletion of IKK2 in hepatocytes does not sensitize these cells to TNF-induced apoptosis but protects from ischemia/reperfusion injury. J Clin Invest 2005;115:849-859.

100. Yang YM, Seki E. TNFa in liver fibrosis. Curr Pathobiol Rep 2015;3: 253-261.

101. Canbay A, Feldstein AE, Higuchi H, Werneburg N, Grambihler A, Bronk SF, et al. Kupffer cell engulfment of apoptotic bodies stimulates death ligand and cytokine expression. Hepatology 2003;38:1188-1198.

102. Canbay A, Friedman S, Gores GJ. Apoptosis: the nexus of liver injury and fibrosis. Hepatology 2004;39:273-278.

103. Noble PW, Albera C, Bradford WZ, Costabel U, Glassberg MK, Kardatzke $D$, et al. Pirfenidone in patients with idiopathic pulmonary fibrosis (CAPACITY): two randomised trials. Lancet 2011;377:17601769.

104. King TE Jr, Bradford WZ, Castro-Bernardini S, Fagan EA, Glaspole I, Glassberg MK, et al. A phase 3 trial of pirfenidone in patients with idiopathic pulmonary fibrosis. N Engl J Med 2014;370:2083-2092.

105. Flores-Contreras L, Sandoval-Rodríguez AS, Mena-Enriquez MG, Lucano-Landeros S, Arellano-Olivera I, Alvarez-Álvarez A, et al. Treatment with pirfenidone for two years decreases fibrosis, cytokine levels and enhances CB2 gene expression in patients with chronic hepatitis C. BMC Gastroenterol 2014;14:131.

106. Komiya C, Tanaka M, Tsuchiya K, Shimazu N, Mori K, Furuke S, et al. Antifibrotic effect of pirfenidone in a mouse model of human nonalcoholic steatohepatitis. Sci Rep 2017;7:44754.

107. Poo JL, Torre A, Aguilar-Ramírez JR, Cruz M, Mejía-Cuán L, Cerda $E$, et al. Benefits of prolonged-release pirfenidone plus standard of care treatment in patients with advanced liver fibrosis: PROMETEO study. Hepatol Int 2020;14:817-827.

108. Kharitonenkov A, Larsen P. FGF21 reloaded: challenges of a rapidly growing field. Trends Endocrinol Metab 2011;22:81-86.

109. Charles ED, Neuschwander-Tetri BA, Pablo Frias J, Kundu S, Luo Y, Tirucherai GS, et al. Pegbelfermin (BMS-986036), PEGylated FGF21, in patients with obesity and type 2 diabetes: results from a randomized phase 2 study. Obesity (Silver Spring) 2019;27:41-49.

110. Itoh N. FGF21 as a hepatokine, adipokine, and myokine in metabolism and diseases. Front Endocrinol (Lausanne) 2014;5:107. 
111. Sanyal A, Charles ED, Neuschwander-Tetri BA, Loomba R, Harrison SA, Abdelmalek MF, et al. Pegbelfermin (BMS-986036), a PEGylated fibroblast growth factor 21 analogue, in patients with nonalcoholic steatohepatitis: a randomised, double-blind, placebocontrolled, phase 2a trial. Lancet 2019;392:2705-2717.

112. Pose E, Trebicka J, Mookerjee RP, Angeli P, Ginès P. Statins: old drugs as new therapy for liver diseases? J Hepatol 2019;70:194-202.

113. Dongiovanni P, Petta S, Mannisto V, Mancina RM, Pipitone R, Karja $\mathrm{V}$, et al. Statin use and non-alcoholic steatohepatitis in at risk individuals. J Hepatol 2015;63:705-712.

114. Nascimbeni F, Aron-Wisnewsky J, Pais R, Tordjman J, Poitou C, Charlotte $F$, et al. Statins, antidiabetic medications and liver histology in patients with diabetes with non-alcoholic fatty liver disease. BMJ Open Gastroenterol 2016;3:e000075.

115. Guaraldi G, Maurice JB, Marzolini C, Monteith K, Milic J, Tsochatzis $\mathrm{E}$, et al. New drugs for NASH and HIV infection: great expectations for a great need. Hepatology 2020;71:1831-1844.

116. Safadi R, Konikoff FM, Mahamid M, Zelber-Sagi S, Halpern M, Gilat $T$, et al. The fatty acid-bile acid conjugate Aramchol reduces liver fat content in patients with nonalcoholic fatty liver disease. Clin Gastroenterol Hepatol 2014;12:2085-2091.e1.

117. Sinha RA, Bruinstroop E, Singh BK, Yen PM. Nonalcoholic fatty liver disease and hypercholesterolemia: roles of thyroid hormones, metabolites, and agonists. Thyroid 2019;29:1173-1191.

118. Zucchi R. Thyroid hormone analogues: an update. Thyroid 2020;30: 1099-1105.

119. Loomba R, Neutel J, Mohseni R, Bernard D, Severance R, Dao M, et al. LBP-20-VK2809, a novel liver-directed thyroid receptor beta agonist, significantly reduces liver fat with both low and high doses in patients with non-alcoholic fatty liver disease: a phase 2 randomized, placebo-controlled trial. J Hepatol 2019;70:e150-e151.

120. Harrison SA, Bashir MR, Guy CD, Zhou R, Moylan CA, Frias JP, et al. Resmetirom (MGL-3196) for the treatment of non-alcoholic steatohepatitis: a multicentre, randomised, double-blind, placebocontrolled, phase 2 trial. Lancet 2019;394:2012-2024.

121. Kliewer SA, Mangelsdorf DJ. Bile acids as hormones: the FXRFGF15/19 pathway. Dig Dis 2015;33:327-331.

122. Alisi A, Ceccarelli S, Panera N, Prono F, Petrini S, De Stefanis C, et al. Association between serum atypical fibroblast growth factors 21 and 19 and pediatric nonalcoholic fatty liver disease. PLoS One 2013;8:e67160.

123. Wojcik M, Janus D, Dolezal-Oltarzewska K, Kalicka-Kasperczyk A, Poplawska K, Drozdz D, et al. A decrease in fasting FGF19 levels is associated with the development of non-alcoholic fatty liver disease in obese adolescents. J Pediatr Endocrinol Metab 2012;25:1089-1093.

124. Zhou M, Wang X, Phung V, Lindhout DA, Mondal K, Hsu JY, et al. Separating tumorigenicity from bile acid regulatory activity for endocrine hormone FGF19. Cancer Res 2014;74:3306-3316.

125. Zhou M, Yang $H$, Learned RM, Tian H, Ling L. Non-cell-autonomous activation of IL-6/STAT3 signaling mediates FGF19-driven hepatocarcinogenesis. Nat Commun 2017;8:15433.

126. Zhou M, Learned RM, Rossi SJ, DePaoli AM, Tian H, Ling L. Engineered FGF19 eliminates bile acid toxicity and lipotoxicity leading to resolution of steatohepatitis and fibrosis in mice. Hepatol Commun 2017;1:1024-1042.

127. Harrison SA, Rinella ME, Abdelmalek MF, Trotter JF, Paredes AH, Arnold HL, et al. NGM282 for treatment of non-alcoholic steatohepatitis: a multicentre, randomised, double-blind, placebocontrolled, phase 2 trial. Lancet 2018;391:1174-1185.

128. Schiff ER, Lee SS, Chao YC, Kew Yoon S, Bessone F, Wu SS, et al. Long-term treatment with entecavir induces reversal of advanced fibrosis or cirrhosis in patients with chronic hepatitis B. Clin Gastroenterol Hepatol 2011;9:274-276.

129. Terrault NA, Bzowej NH, Chang KM, Hwang JP, Jonas MM, Murad $\mathrm{MH}$, et al. AASLD guidelines for treatment of chronic hepatitis $\mathrm{B}$. Hepatology 2016;63:261-283.

130. Akhtar E, Manne V, Saab S. Cirrhosis regression in hepatitis C patients with sustained virological response after antiviral therapy: a meta-analysis. Liver Int 2015;35:30-36.

131. Bachofner JA, Valli PV, Kröger A, Bergamin I, Künzler P, Baserga A, et al. Direct antiviral agent treatment of chronic hepatitis $C$ results in rapid regression of transient elastography and fibrosis markers fibrosis-4 score and aspartate aminotransferase-platelet ratio index. Liver Int 2017;37:369-376.

132. Dolmazashvili E, Abutidze A, Chkhartishvili N, Karchava M, Sharvadze $L$, Tsertsvadze T. Regression of liver fibrosis over a 24-week period after completing direct-acting antiviral therapy in patients with chronic hepatitis $C$ receiving care within the national hepatitis C elimination program in Georgia: results of hepatology clinic HEPA experience. Eur J Gastroenterol Hepatol 2017;29:1223-1230.

133. Borssén ÅD, Palmqvist $R$, Kechagias $S$, Marschall HU, Bergquist $A$, Rorsman $F$, et al. Histological improvement of liver fibrosis in welltreated patients with autoimmune hepatitis: a cohort study. Medicine (Baltimore) 2017:96:e7708.

134. Corpechot C, Carrat F, Bonnand AM, Poupon RE, Poupon R. The effect of ursodeoxycholic acid therapy on liver fibrosis progression in primary biliary cirrhosis. Hepatology 2000;32:1196-1199. 